\title{
RENOVAL CHARGE TECHNIC APPLIED TO A BIFACIAL SOLAR CELL UNDER CONSTANT MAGNETIC FIELD
}

\section{S. MBODJI, A. S. MAIGA, M. DIENG, A. WEREME AND G. SISSOKO}

(Received 30, May 2007; Revision Accepted 19, September 2008)

\section{ABSTRACT}

An $n^{+}-p-p^{+}$bifacial solar cell under constant magnetic field is placed in a fast-switch-interrupted circuit and submitted to a constant multi-spectral illumination. The transient decay occurs between two steady states through operating points depending on two variable resistors; this allows us to obtain a transient decay at any operating point of the I-V curve of the solar cell, from the short circuit to the open one. The influence of magnetic field on the transient photocurrent has been studied using Matlab Simulink simulations.

These simulations lead to an equivalent circuit of the bifacial cell in transient state assuming that the photocurrent is the diffused.

PACS: $73.50 . P z$

KEYWORDS: Bifacial Solar cell; Equivalent electric circuit, Magnetic field.

\section{INTRODUCTION}

This work presents a transient study of a bifacial silicon solar cell under magnetic field and submitted to constant white light (Figure 1). To perform the simulation with Matlab Simulink, the bifacial cell in the experimental setup has been replaced by an equivalent electrical circuit (Mialhe, et al., 1992, pp 2317-31), (Barro, et al., 2004) and the influence of the magnetic field on the transient photocurrent has been studied. This equivalent electrical circuit includes the photocurrent source (Colomb, et al., 1992), the device depletion capacitance, the inductance, the series resistance $\mathrm{Rs}_{\alpha}$, and the shunt resistance $\mathrm{Rsh}_{\alpha}$. Rc is the external load.

\section{THEORY}

The excess minority carrier concentration is obtained by solving the equation of continuity (Equation 1) with boundary conditions (Equation 2 and 3 ) which include interface states in the bifacial solar cell.

$$
D^{*} \cdot \frac{\partial^{2} \delta_{\alpha}(\mathrm{x}, \mathrm{t})}{\partial^{2} \mathrm{x}}-\frac{\delta_{\alpha}(\mathrm{x}, \mathrm{t})}{\tau_{\alpha}}=\frac{\partial \delta_{\alpha}(\mathrm{x}, \mathrm{t})}{\partial \mathrm{t}}
$$

$\mathrm{D}^{*}$ and $\tau_{\alpha}$ represent respectively minority carrier diffusion and lifetime under constant magnetic field [4].

The boundary conditions are:

- at the $p$-n interface $(x=0)$

$\left.\mathrm{D}^{*} \cdot \frac{\partial \delta_{\alpha}(\mathrm{x}, \mathrm{t})}{\partial \mathrm{x}}\right|_{\mathrm{x}=0}=\mathrm{Sf}_{\alpha} \cdot \delta_{\alpha}(0, \mathrm{t})$

- $\quad$ at the back side of the cell $(x=H)$

S. Mbodji, Laboratoire des Semiconducteurs et d'Energie solaire, Département de Physique, Faculté des Sciences et Techniques, Université Cheikh Anta Diop, Dakar, Senegal.

A. S. Maiga*, Section de Physique Appliquée, UFR de Sciences Appliquées et de Technologie, Université Gaston Berger de Saint-Louis Senegal

*Laboratoire des Semiconducteurs et d'Energie solaire, Département de Physique, Faculté des Sciences et Techniques, Université Cheikh Anta Diop, Dakar, Senegal.

M. Dieng, Laboratoire des Semiconducteurs et d'Energie solaire, Département de Physique, Faculté des Sciences et Techniques, Université Cheikh Anta Diop, Dakar, Senegal.

A. Wereme, Laboratoire des Matériaux et Environnement, Département de Physique, UFR-SEA, Université de Ouagadougou, Burkina Faso.

G. Sissoko, Laboratoire des Semiconducteurs et d'Energie solaire, Département de Physique, Faculté des Sciences et Techniques, Université Cheikh Anta Diop, Dakar, Senegal. 
$\left.\mathrm{D}^{*} \cdot \frac{\partial \delta_{\alpha}(\mathrm{x}, \mathrm{t})}{\partial \mathrm{x}}\right|_{\mathrm{x}=\mathrm{H}}=-\mathrm{Sb}_{\alpha} \cdot \delta_{\alpha}(\mathrm{H}, \mathrm{t})$

$\mathrm{Sf}_{\alpha}$ is the junction recombination velocity which takes into account the intrinsic recombination velocity $\mathrm{Sf}_{0}$ and $\mathrm{Sb}_{\alpha}$ is the back surface recombination velocity.

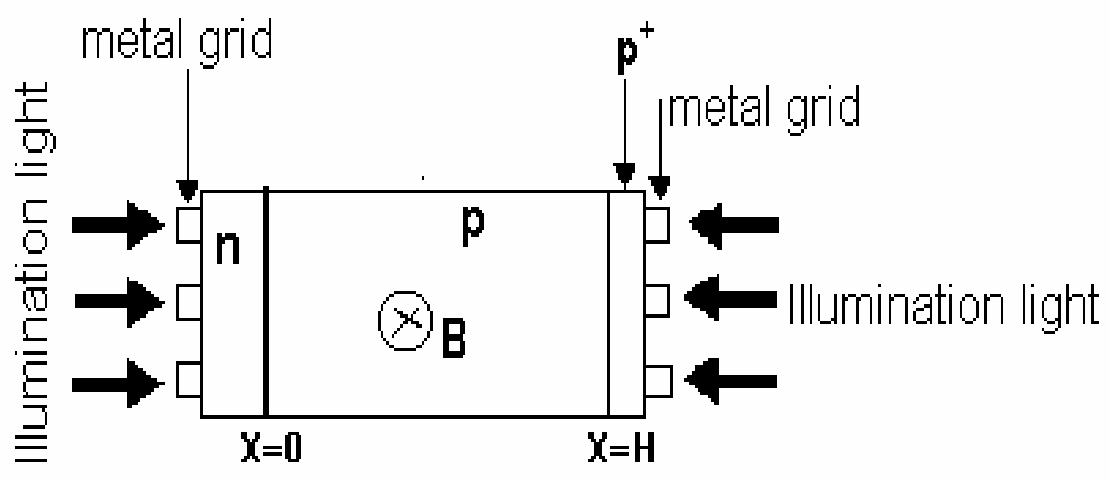

Figure 1: Bifacial solar cell under constant magnetic field

The steady state excess minority carrier density is:

$$
\begin{aligned}
& \delta_{\alpha}(\mathrm{x})=\mathrm{A}_{\alpha} \cdot \cosh \left(\frac{\mathrm{x}}{\mathrm{L}^{*}}\right)+\mathrm{B}_{\alpha} \cdot \sinh \left(\frac{\mathrm{x}}{\mathrm{L}^{*}}\right) \\
& +\sum_{\mathrm{i}=1}^{3} \mathrm{~K}_{\mathrm{i}} \cdot\left[\varepsilon \cdot \exp \left(-\mathrm{b}_{\mathrm{i}}(\mathrm{H}-\mathrm{x})\right)+\gamma \cdot \exp \left(-\mathrm{x} \cdot \mathrm{b}_{\mathrm{i}}\right)\right]
\end{aligned}
$$

with: $\varepsilon$ and $\gamma$ taking the values in table 1 .

Table1. Range of $\varepsilon$ and $\gamma$

\begin{tabular}{|l|c|c|}
\hline Illumination mode & $\varepsilon$ & $\gamma$ \\
\hline $\begin{array}{l}\text { Front side illumination } \\
(\alpha=\mathrm{fr})\end{array}$ & 1 & 0 \\
\hline $\begin{array}{l}\text { Rear side illumination } \\
(\alpha=\mathrm{re})\end{array}$ & 0 & 1 \\
\hline Simultaneous illumination $(\alpha=\mathrm{s})$ & 1 & 1 \\
\hline
\end{tabular}

$\mathrm{K}_{\mathrm{i}}$ is given by :

$\mathrm{K}_{\mathrm{i}}=-\mathrm{a}_{\mathrm{i}} \cdot\left[\mathrm{D}^{*} \cdot\left(\mathrm{b}_{\mathrm{i}}^{2}-\frac{1}{\mathrm{~L}^{2}}\right)\right]^{-1}$

where $a_{i}$ and $b_{i}$ are coefficients deduced from modelling of the generation rate overall radiations in the solar spectrum (SZE, 1981, p.145)

The subscript $\alpha$ indicates how the solar cell is illuminated: front side $(\alpha=\mathrm{fr})$, rear side $(\alpha=\mathrm{re})$ or simultaneous illumination $(\alpha=s)$. 
Constants $A_{\alpha}$ and $B_{\alpha}$ are determined by means of boundary conditions (Equation 2) and (Equation 3 ) where the minority carrier density is replaced with (Equation 4).

(Equation 1) and boundary conditions (Equation 2 and 3) constitute a typical Sturm-Liouville's system (BASU and SINGH, 1994, pp.317-329) from which we obtain the minority carriers density in transient state:

$\delta_{\alpha}(\mathrm{x}, \mathrm{t})=\sum_{\mathrm{n}} \mathrm{X}_{\alpha, \mathrm{n}}(\mathrm{x}) \mathrm{T}_{\alpha, \mathrm{n}}(0) \exp \left(-\frac{1}{\tau_{\mathrm{c}, \alpha, \mathrm{n}}} \mathrm{t}\right)$

$\mathrm{X}_{\alpha, \mathrm{n}}$ and $\mathrm{T}_{\alpha, \mathrm{n}}(0)$ are deduced from $\delta_{\alpha}(\mathrm{x}, \mathrm{t})$ by normalization and Fourier transform.

$\tau_{\mathrm{c}, \alpha, \mathrm{n}}$ is the decay time constant given by :

$\frac{1}{\tau_{\alpha}}=\frac{1}{\tau_{\mathrm{c}, \alpha, \mathrm{n}}}-\omega_{\alpha, \mathrm{n}}{ }^{2}$

where $\omega_{\alpha, n}$ is the eigenvalue of the transcendental equation:

$\tan \left(\frac{\mathrm{H} \cdot \omega_{\alpha}}{\sqrt{\mathrm{D}^{*}}}\right)=\frac{\omega_{\alpha} \cdot \sqrt{\mathrm{D}^{*}}\left(\mathrm{Sf}_{\alpha}+\mathrm{Sb}_{\alpha}\right)}{\mathrm{D}^{*} \cdot \omega_{\alpha}^{2}-\mathrm{Sf}_{\alpha} \cdot \mathrm{Sb}_{\alpha}}$

\section{SIMULATION}

To perform the simulation with Matlab Simulink, the bifacial cell in the original setup has been replaced by an equivalent electrical circuit, Figure2, (Barro, et al., 2004) and the influence of the magnetic field on the transient photocurrent has been studied. The Simulink model of the Solar cell equivalent Circuit is shown in Figure 3.

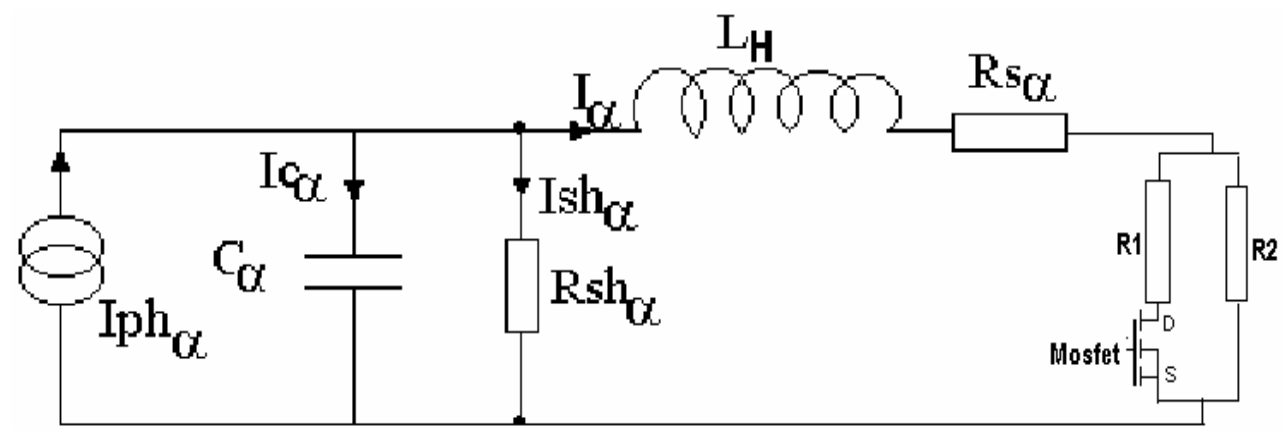

Figure 2: Solar cell equivalent Circuit with R1, R2 and the switch.

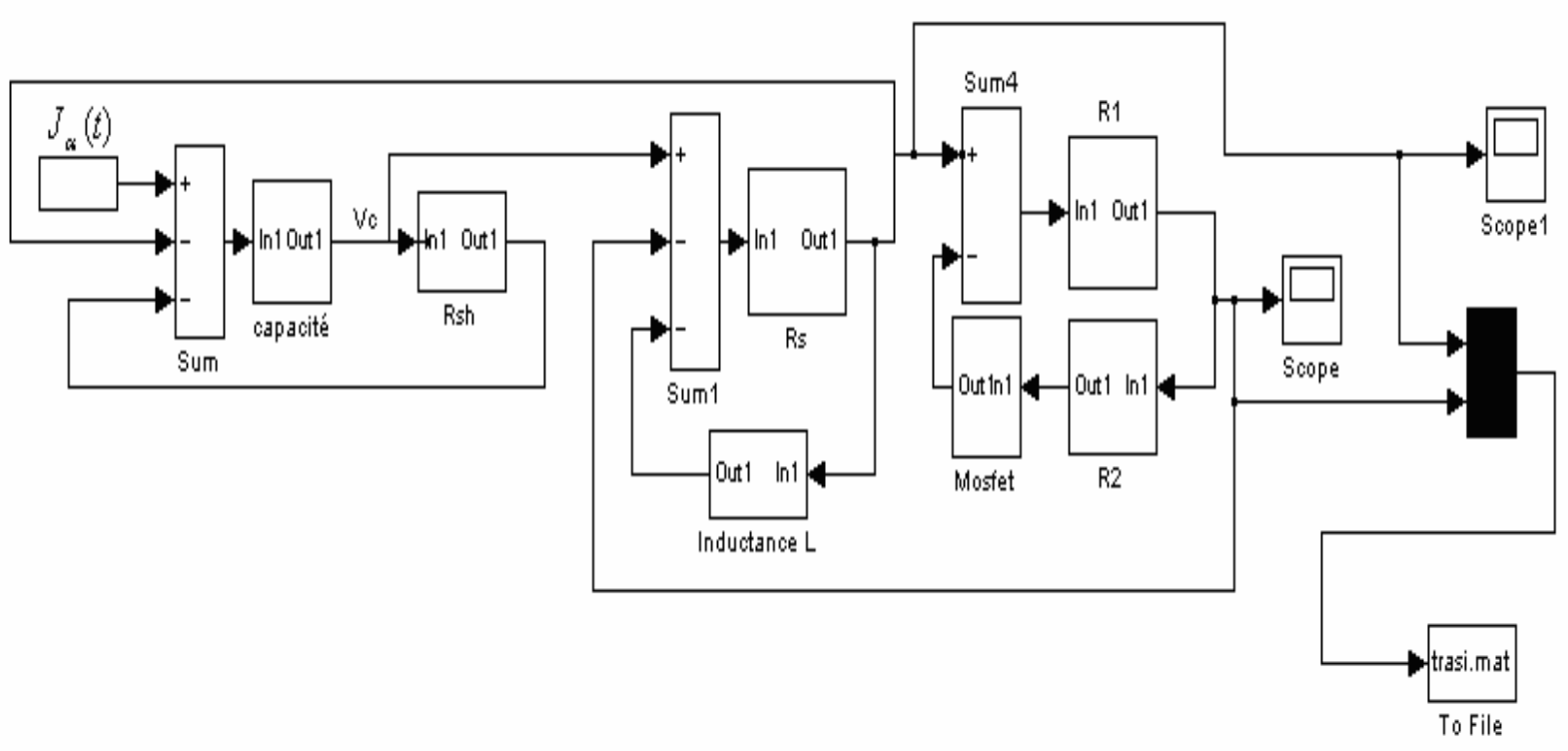

Figure 3: Simulink model of the Solar cell equivalent Circuit with R1,R2 and the switch 
When the time, $\mathrm{t}<0$ the solar cell is in parallel with the resistor R2 giving the potential V2 corresponding to the operating point F2. At time $t=0$, the fast switch begins turning on and at time $t>0$ is completely turned on. It then connects the resistor R2 in parallel with the solar cell and the resistor R1; The voltage V2 drops from V2 to V1 corresponding to the new operating point F1 as it can be seen on Figure 4.

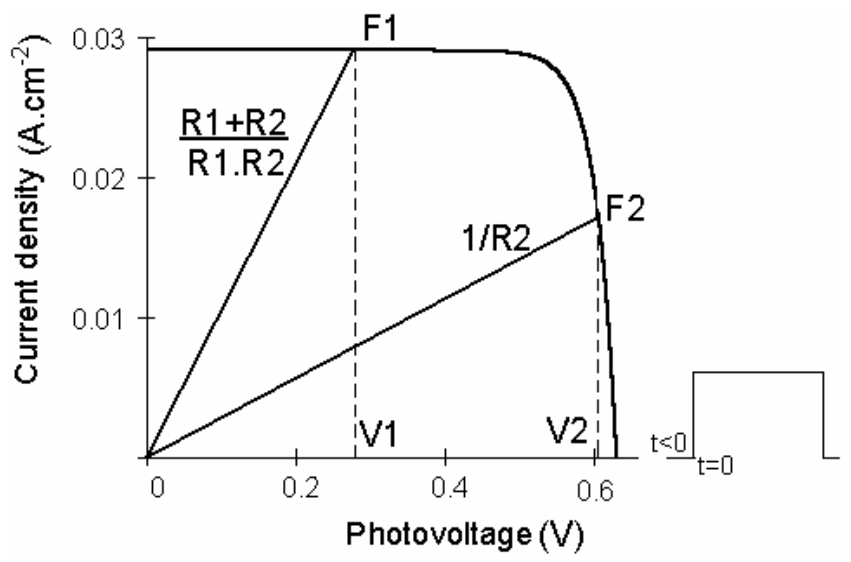

Figure 4: Illuminated I-V curve

\section{RESULTS AND DISCUSSIONS}

We present in Figures 5, 6 and 7 the transient photocurrent decay for different solar cells and different magnetic fields $(B=0 T, B=0.001 T$, and $B=0.005 T)$.

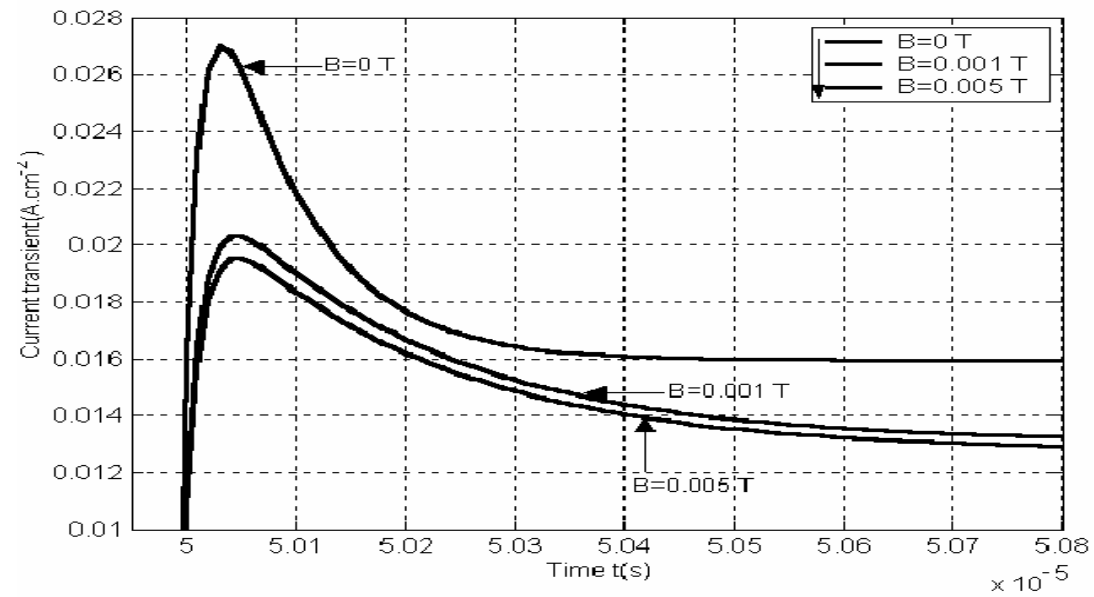

Figure 5: Transient photocurrent decay (front side illumination)

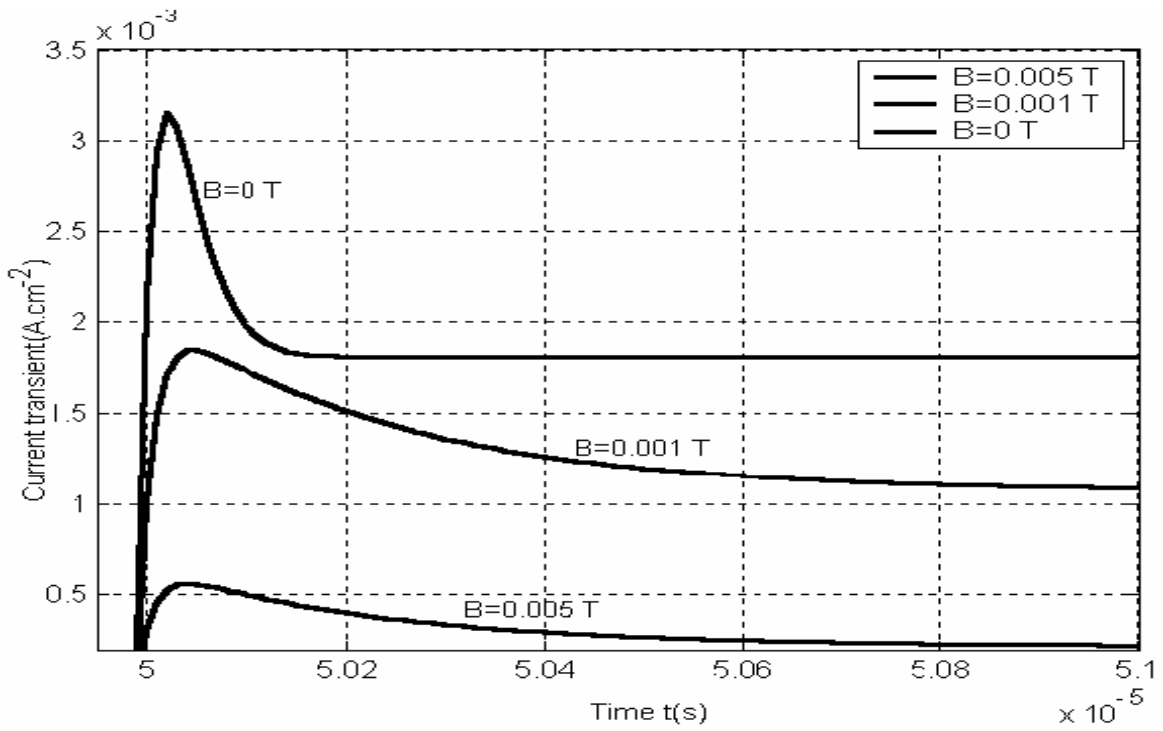

Figure 6: Transient photocurrent decay (rear side illumination) 


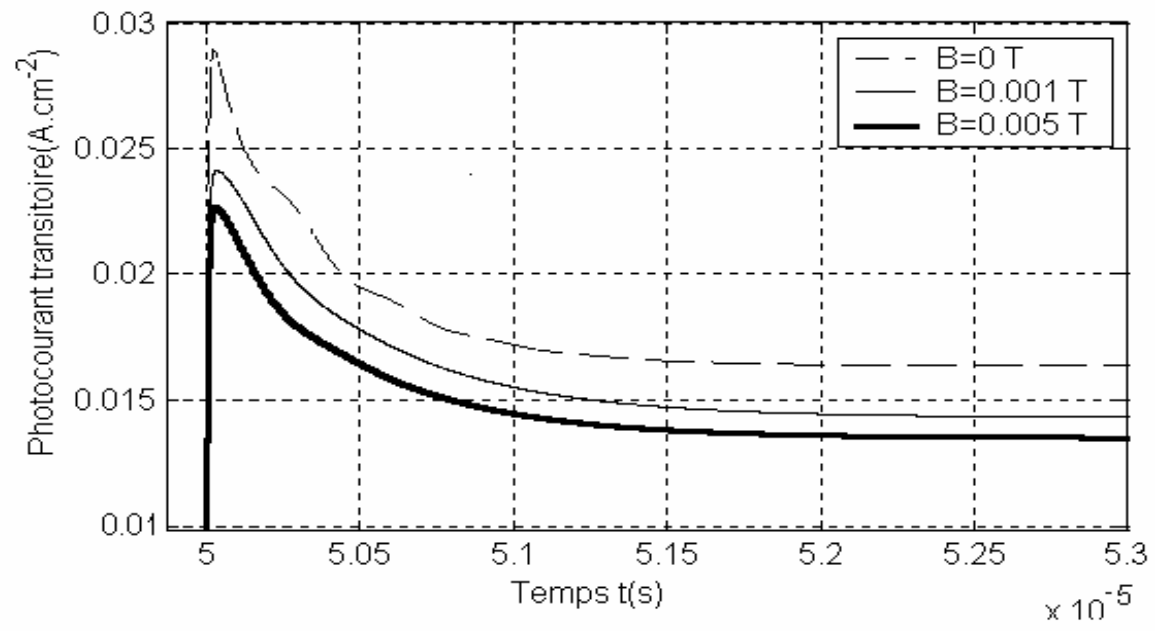

Figure 7: Transient photocurrent decay (simultaneous illumination)

The transient photocurrent decreases if the magnetic field increases for each illumination.

Based on Figure 8 we can write the following equation:

$\left.\mathrm{L}_{\mathrm{H}} \cdot \mathrm{I}_{\alpha} \ddot{(} \mathrm{t}\right)+\left(\mathrm{Rc}-\mathrm{Rs}_{\alpha}\right) \cdot \mathrm{I}_{\alpha}(\mathrm{t})+\frac{\mathrm{I}_{\alpha}(\mathrm{t})}{\mathrm{C}_{\alpha}}=\frac{1}{\mathrm{C}_{\alpha}} \cdot\left(\operatorname{Iph}_{\alpha}(\mathrm{t})-\mathrm{Ish}_{\alpha}(\mathrm{t})\right)$

Neglecting $I_{\text {sh } \alpha}(t)$, Equation 8 becomes :

$\mathrm{L}_{\mathrm{H}} \cdot \ddot{\mathrm{I}_{\alpha}} \ddot{(\mathrm{t})}+\left(\mathrm{Rc}-\mathrm{Rs}_{\alpha}\right) \cdot \mathrm{I}_{\alpha}(\mathrm{t})+\frac{\mathrm{I}_{\alpha}(\mathrm{t})}{\mathrm{C}_{\alpha}}=\frac{1}{\mathrm{C} \alpha} \mathrm{I}_{\mathrm{ph} \alpha}(\mathrm{t})$

where

$J_{\alpha}(t)=q \cdot D^{*} \cdot B_{\alpha, 0} \cdot \omega_{\alpha, 0} \cdot T_{\alpha, 0}(0) \cdot \exp \left[-\left(\omega_{\alpha, 0}+\frac{1}{\tau_{\alpha}}\right) \cdot t\right.$

The series resistance $\mathrm{Rs}_{\alpha}$ and the capacitance $\mathrm{C}_{\alpha}$ depend on the magnetic field.

(Sissoko et al., 1998, pp.1852-1855), (Shockley, 1949, p 435), (Muller and Kamins,1986),(Bierhals, et al., 2000, pp142-145), (Ricaud,1997)

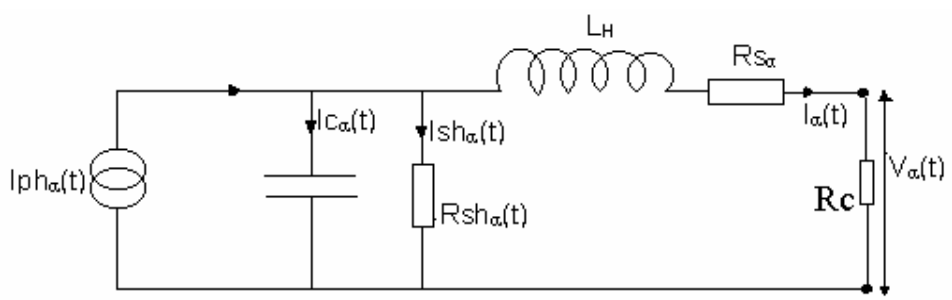

Figure 8: Electrical equivalent circuit of the solar cell in transient state

Solutions of equation (9) depend on the sign of $\Delta$ expressed below:

$$
\Delta=\left(\mathrm{Rc}-\mathrm{Rs}_{\alpha}\right)^{2}-\frac{4 \cdot \mathrm{L}_{\mathrm{H}}}{\mathrm{C}_{\alpha}}
$$

We only investigate solutions corresponding to $\Delta>0$ and $\Delta<0$.

When $\Delta>0$ the solution can be expressed by:

$$
I_{\alpha}(t)=A 1 \exp (-b . t)+A 2 \cdot \exp (-c \cdot t)+K \cdot \exp (-a . t)
$$

Where

$$
\mathrm{a}=\omega_{\alpha, 0}+\frac{1}{\tau_{\alpha}} \quad \mathrm{b}=\frac{\mathrm{R}_{0}}{2 \cdot \mathrm{L}_{\mathrm{H}}}-\sqrt{\left(\frac{\mathrm{R}_{0}^{2}}{2 \cdot \mathrm{L}_{\mathrm{H}}}\right)^{2}-\frac{1}{\mathrm{~L}_{\mathrm{H}} \cdot \mathrm{C}_{\alpha}}} \quad c=\frac{R_{0}}{2 \cdot L_{H}}+\sqrt{\left(\frac{R_{0}^{2}}{2 \cdot L_{H}}\right)^{2}-\frac{1}{L_{H} \cdot C_{\alpha}}} \quad \text { and } \mathrm{R}_{0}=\mathrm{Rc}-\mathrm{Rs}
$$


Constants $\mathrm{A} 1$ and $\mathrm{A} 2$ can be calculated for two points : at the maximum current (dl $/ \mathrm{dt}=0$, beginning of the decay) and when the current I is approximately constant corresponding to the end of the decay ( greater value of time, see for example Figure 6$) \mathrm{l}(\mathrm{t})=\mathrm{Is}$ at $\mathrm{t}=\mathrm{ts}$.

Constants $A_{1}, A_{2}$ and $K$ depend on $C_{\alpha}$, Rs $\alpha$, sd $\omega_{\alpha, 0}$, ts, $\tau_{\alpha}, L_{H}$ and Rc. $L_{H}$ and $\tau_{\alpha}$ are fixed at $0.001 H$ and $4.5 \mu s$ respectively.

Based on the relation $V_{\alpha}(t)=R c . I_{\alpha}(t)$, we plotted the photovoltage $V_{\alpha}$ versus the time $t$ for each illumination mode.

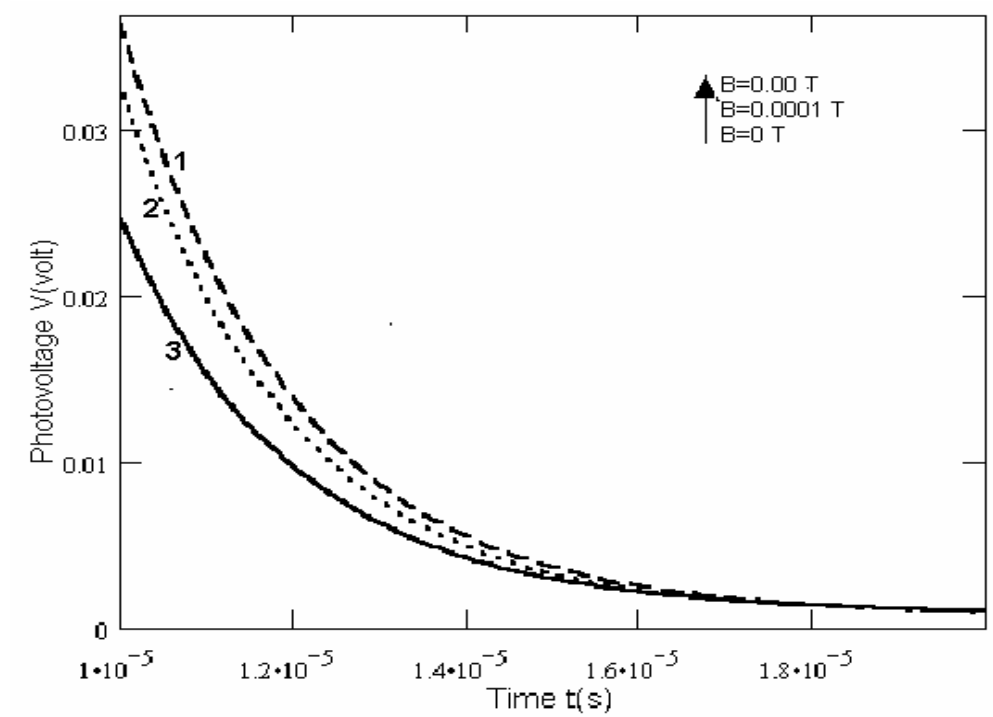

Figure 9: Transient photovoltage decay: front side illumination $\left(\mathrm{H}=0.02 \mathrm{~cm}, \tau_{\alpha}=4.5 \mu \mathrm{m}\right)$

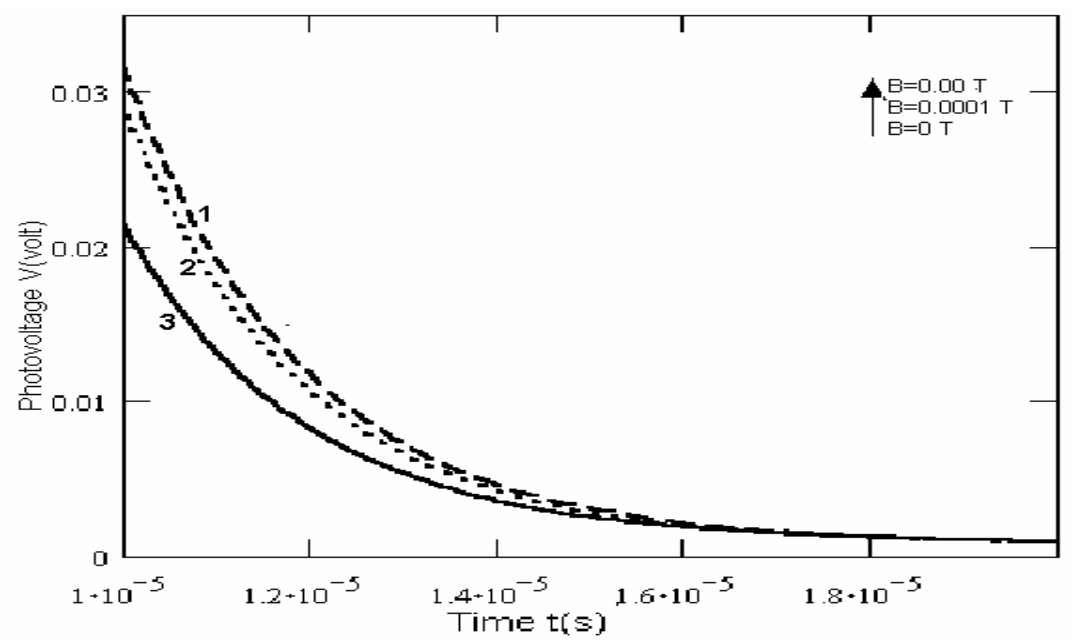

Figure 10: Transient photovoltage decay : rear side illumination $(\mathrm{H}=0.02 \mathrm{~cm}, \tau \alpha=4.5 \mu \mathrm{m})$

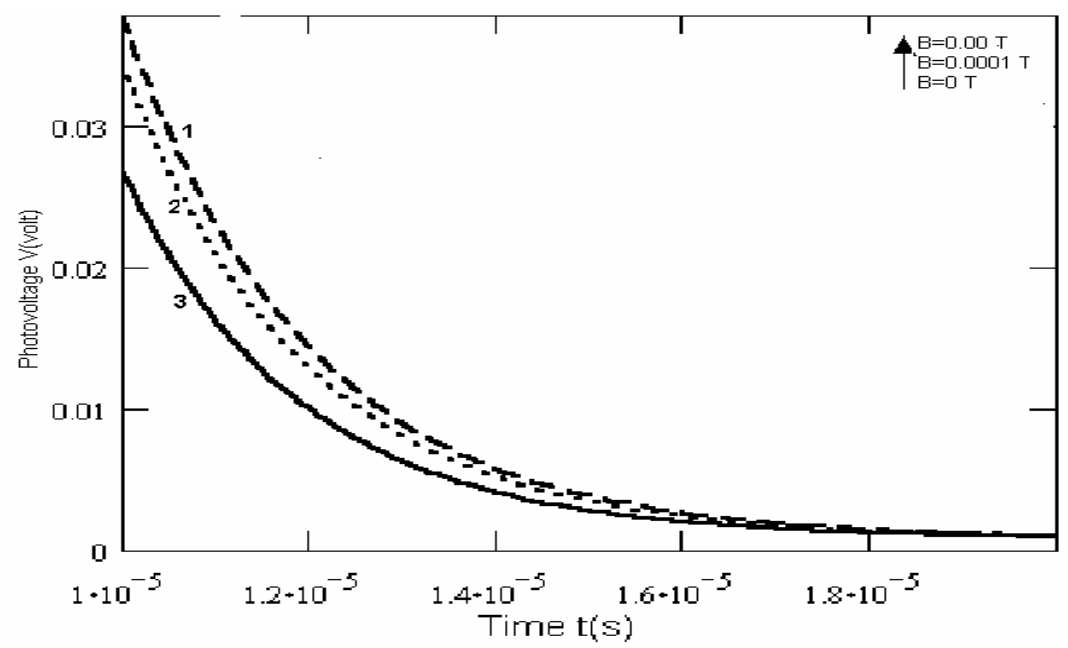

Figure 11: Transient photovoltage decay: simultaneous illumination $\left(\mathrm{H}=0.02 \mathrm{~cm}, \tau_{\alpha}=4.5 \mu \mathrm{m}\right)$ 
Figures 9, 10 and 11 show that under the influence of the magnetic field the photovoltage decay increases when the solar cell is illuminated by front side, rear side and both front side and back-side.

In the case, $\Delta<0$ the solution can be expressed by:

$I_{\alpha}(t)=\exp \left(\alpha_{0}\right)\left[A_{1}^{\prime} \cdot \cos (\beta . t)+A_{2}^{\prime} \cdot \sin (\beta . t)\right]+K \cdot \exp (-a . t)$

where,

$$
\alpha_{0}=-\frac{\mathrm{R} 0}{2 . \mathrm{L}_{\mathrm{H}}}, \beta=\sqrt{\frac{1}{\mathrm{~L}_{\mathrm{H}} \cdot \mathrm{C}_{\alpha}}-\left(\frac{\mathrm{R} 0}{2 \cdot \mathrm{L}_{\mathrm{H}}}\right)^{2}}
$$

$A_{1}$ 'and $A_{2}$ ' are calculated by the same way as $A 1$ and $A 2$. Figure12 to 14 present the transient photovoltage versus the time $t(s)$ when the solar cell is illuminated respectively by front side, back side and both front and back-side.

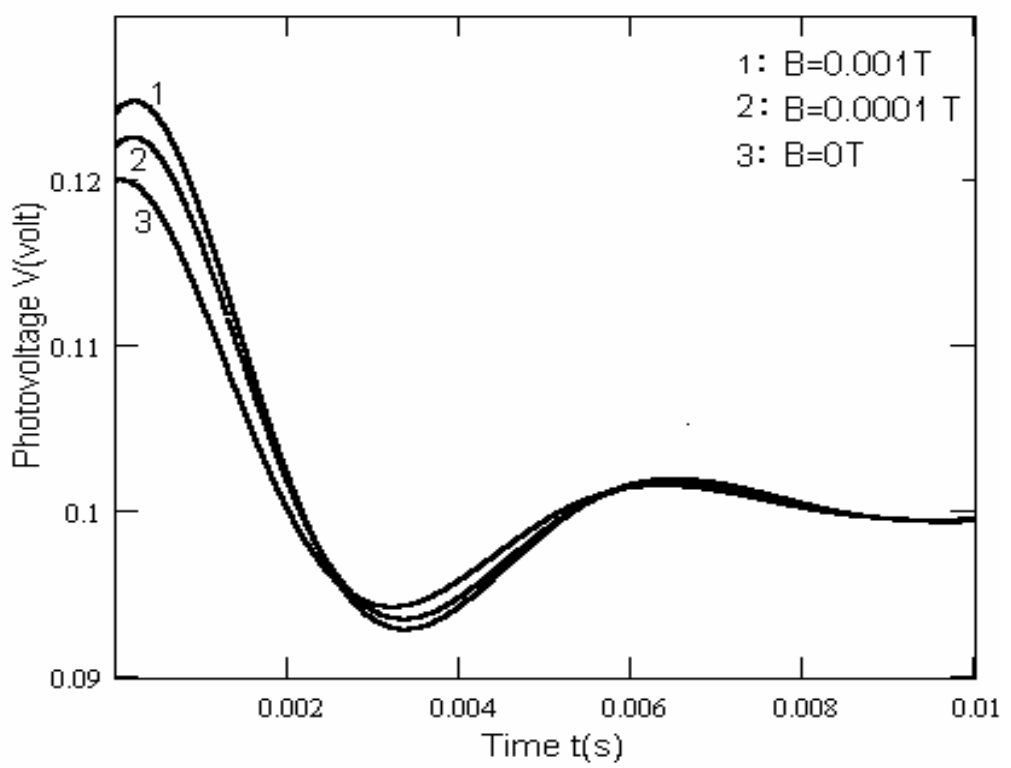

Figure 12: Transient photovoltage decay: front side illumination $\left(\mathrm{H}=0.02 \mathrm{~cm}, \tau_{\alpha}=4.5 \mu \mathrm{m}\right)$.

When $\Delta$ is negative, the photovoltage is sinusoidal for each illumination (Figure 12 to 14) and we notice three parts: the first is where the photovoltage increases with the magnetic field, in the second the transient photovoltage doesn't follow the increase of the magnetic field and the last part is where the photovoltage is approximately constant for the three magnetic field.

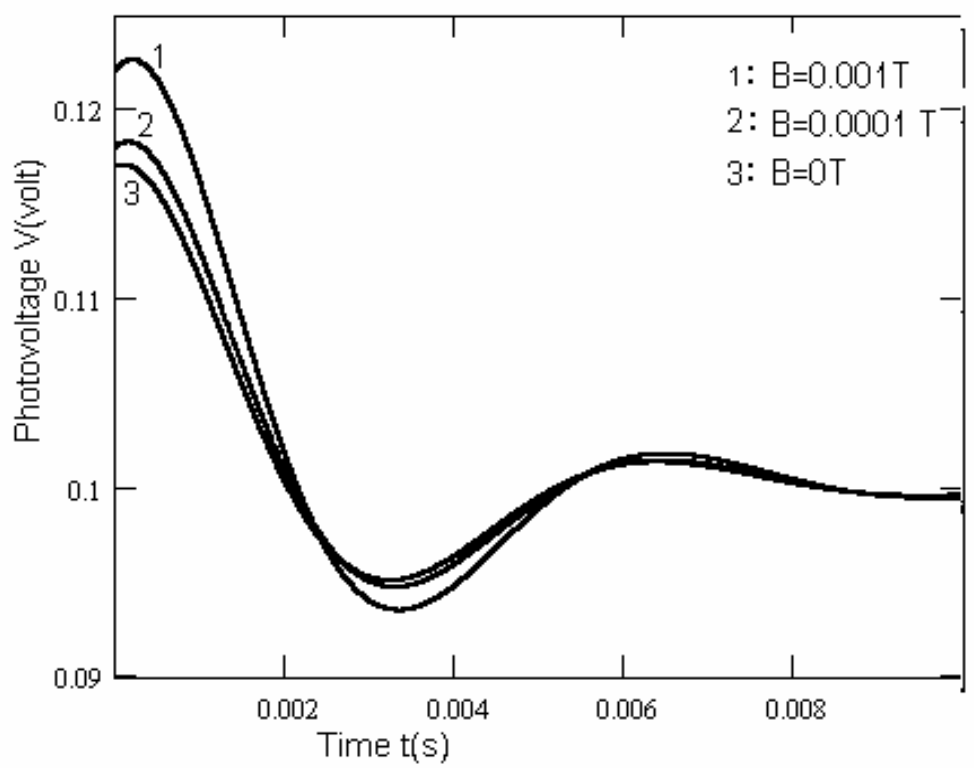

Figure 13: Transient photovoltage decay: rear side illumination $(\mathrm{H}=0.02 \mathrm{~cm}, \tau \alpha=4.5 \mu \mathrm{m})$. 


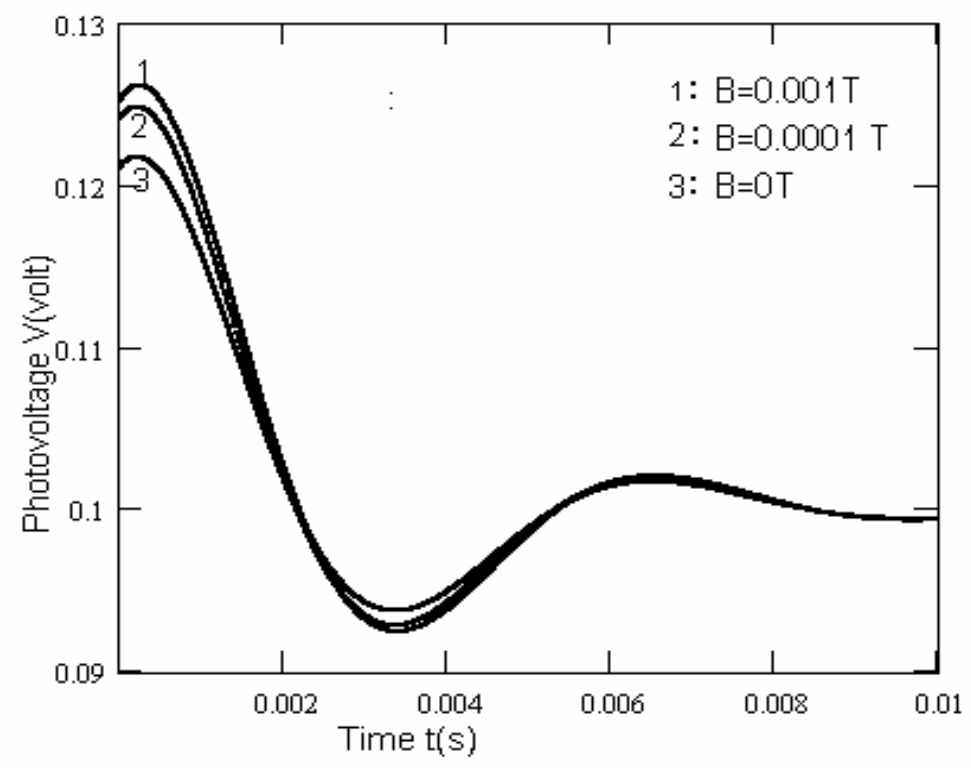

Figure 14: Transient photovoltage decay: simultaneous illumination. $(\mathrm{H}=0.02 \mathrm{~cm}, \tau \alpha=4.5 \mu \mathrm{m})$.

Thus, the case $\Delta>0$ is more interesting than the case $\Delta<0$.

The exponential fit of the transient photovoltage when $\Delta>0$ can give values of b, $c$ and a. Value of Rc is fixed, Rs $s_{\alpha}$ is negligible compared to Rc for front side illumination and for simultaneous illumination of both front and back-side; $b$ and $\mathrm{c}$ can be taken as a system of equations which system lead to the values of $L_{H}$ and $C_{\alpha}$ for these two illumination modes. With the value of a the lifetime $\tau_{\alpha}$ is calculated assuming that the eigenvalue of the fundamental mode, $\omega_{\alpha, 0}$ is known (Barro, et al., 2004).

\section{CONCLUSION}

A theoretical study of a bifacial solar cell under constant magnetic field and under constant illumination was presented. The effect of the magnetic field has been exhibited on both photocurrent and photovoltage for each illumination mode. Based on theoretical and simulation results, the electrical parameters $L_{H}, C_{\alpha}, R_{S}$ and the minority carriers' lifetime $\tau_{\alpha}$ are determined for each illumination mode.

\section{REFERENCES}

Barro, F.I., Mbodji, S., Ndiaye, A. L., Madougou, S., Zerbo, I., Zougmore, F. and Sissoko, G., 2004. European Photovoltaic Solar Energy Conference and Exhibition, Poster 1AV2.57.

Basu, P.K. and Singh, S.N., 1994. Solar Energy Materials and Solar Cells, 33: 317-329.

Betser, Y., Ritter, D., Bahir, G., Cohen, S. and Sperling, J., 1995. Appl. Phys. Lett, 67 (13): 1883-1884.

Bierhals, A., Metz, A. and Hezel, R., 2000. European photovoltaic solar conference, Glasgow, UK, pp142-145.

Colomb, C.M., Stockman, S.A., Varadarajan, S. and Stillman, G.E.,1992. Appl Phys. Lett. 60.

Mialhe, P., Sissoko, G., Pelanchon, F., and Salagnan, J.M., 1992. J. Phys. III (2): 2317-31.

Muller, R. S. and Kamins, T.I., 1986. Device Electronics for Integrated Circuit $2^{\text {nd }}$ Edition Wiley, New York USA.

Ricaud A., 1997. Photopiles solaires Presses Polytechniques et Universitaires romandes, Lausanne, Suisse.

Shockley, W., 1949. Bell Syst. Techn. Journal, 28: 435.

Sissoko, G., Dieng, B., Corréa, A., Adji, M., and Azilinon, D., 1998. World Renewable Energy Congress, pp 18521855.

SZE, S.M., 1981. Physics of semiconductor devices, 2nd Edition, Wiley Interscience, New-York USA, 145 pp. 